\title{
Honey bee success predicted by landscape composition in Ohio, USA
}

Douglas B Sponsler, Reed M Johnson

Foraging honey bees (Apis mellifera L.) can routinely travel as far as several kilometers from their hive in the process of collecting nectar and pollen from floral patches within the surrounding landscape. Since the availability of floral resources at the landscape scale is a function of landscape composition, apiculturists have long recognized that landscape composition is a critical determinant of honey bee colony success. Nevertheless, very few studies present quantitative data relating colony success metrics to local landscape composition. We employed a beekeeper survey in conjunction with GIS-based landscape analysis to model colony success as a function of landscape composition in the State of Ohio, USA, a region characterized by intensive cropland, urban development, deciduous forest, and grassland. We found that colony food accumulation and wax production were positively related to cropland and negatively related to forest and grassland, a pattern that may be driven by the abundance of dandelion and clovers in agricultural areas compared to forest or mature grassland. Colony food accumulation was also negatively correlated with urban land cover in sites dominated by urban and agricultural land cover, which does not support the popular opinion that the urban environment is more favorable to honey bees than cropland. 
1 PeerJ

2 Honey bee success predicted by landscape composition in Ohio, USA

3 D. B. Sponsler* and R. M. Johnson

4 The Ohio State University, Department of Entomology

51680 Madison Ave., Wooster, OH 44691

$6 *$ corresponding author

7 D. B. Sponsler

8 The Ohio State University

9 Department of Entomology

101680 Madison Ave.

11 Wooster, $\mathrm{OH} 44691$

12 Phone: 330-749-2171

13 Email: sponsler.18@,osu.edu 
Honey bees (Apis mellifera, L.) exist in large, eusocial colonies that require massive and sustained inputs of floral nectar and pollen. They meet this demand by foraging at an extremely large spatial scale and with rapid responsiveness to changes in the surrounding floral community (Visscher \& Seeley, 1982; Seeley, 1995). Depending on local floral availability, colonies may routinely forage over an area of more than $100 \mathrm{~km}^{2}$ (Seeley, 1995), and much larger ranges have been reported under extreme conditions (Eckert, 1931; Beekman \& Ratnieks, 2001).

Because honey bee foraging is a decidedly landscape-scale process, one should expect landscape composition to interact meaningfully with colony nutrition and overall colony success. While the plausibility of such a relationship is widely acknowledged (Steffan-Dewenter \& Kuhn, 2003; Naug, 2009; vanEngelsdorp \& Meixner, 2010; Härtel \& Steffan-Dewenter, 2014), and the importance of apiary location is axiomatic among practicing beekeepers, there are very few published studies that quantitatively measure colony success in response to local landscape variables. As rapid landscape conversion continues as a global phenomenon, and beekeepers in many regions continue to suffer unsustainable losses, the task of refining and expanding our knowledge of honey bee landscape ecology takes on obvious urgency.

Several studies have indirectly explored the relationship between landscape and colony success by analyzing the spatial information encoded in the honey bee dance language (von Frisch, 1967). Waddington et al. (1994) found that colonies located in two suburban landscapes tended to forage over a smaller area and with a less clumped distribution than a previously studied colony located in a temperate deciduous forest (Visscher and Seeley, 1982), suggesting that suburban landscapes might provide richer and more evenly distributed resource patches. Similarly, Garbuzov et al. (2014) found that colonies in the city of Brighton, UK, concentrated most of their foraging within city limits rather than venturing into surrounding countryside that was well within their foraging range. Conversely, Beekman and Ratnieks (2001) observed remarkably long-distance foraging under conditions of apparently scarce local resources in a 
40 suburban landscape and highly rewarding resources in outlying seminatural heather moors. In

41 agricultural landscapes, honey bee foraging patterns suggest that pollen sources can be scarcer

42 and floral patches less spatially and temporally variable in highly simplified cropping systems

43 compared to more structurally complex habitats (Steffan-Dewenter \& Kuhn, 2003), while

44 conservation management within farmlands can increase the availability of bee-attractive flora

45 (Couvillon, Schürch \& Ratnieks, 2014).

46 Landscape composition can also influence the type and quality of pollen foraged by honey

47 bees. Donkersley et al. (2014) found that the protein content of "beebread" (processed pollen

48 stored by honey bees) was negatively correlated with agricultural land cover and positively

49 correlated with broad-leaf forest, improved grassland, and urban land cover.

Two recent studies have directly related colony success to local landscape variables

51 (Sande et al., 2009; Odoux et al, 2014). In the dry coastal forest habitat of southeastern Kenya,

52 Sande et al. (2009) found that a colony's honey production was positively correlated with its

53 proximity to forest patches. Odoux et al. (2014) similarly found that colony size was positively

54 correlated with forest land cover in the intensively agricultural landscape of central-western

55 France.

56 Among non-peer-reviewed sources, there is a widely circulated opinion that honey bee

57 success is favored by urban/suburban landscapes, especially in comparison to cropland (Graham,

58 1992; New York Times, 2008; Wilson-Rich, 2012). These claims remain unsubstantiated but

59 plausible given the ostensibly positive effects of suburban land use suggested by Waddington et

60 al. (1994) and the more direct evidence supporting the favorability of suburban land use for

61 bumble bees (Hymenoptera: Bombus, Latreille) living in predominantly agricultural areas

62 (Goulson et al., 2002; 2010).

63 Here, we present a quantitative study of honey bee colony success in relation to landscape

64 composition in the State of Ohio, USA, a region characterized by a mixture of intensive cropland, 
65 deciduous forest, grassland, and urban development. While there are many ways to measure

66 colony success, we focused on four metrics that are highly relevant to beekeepers and easily

67 assessed through simple hive inspection: honey and pollen accumulation, wax production, adult

68 population, and brood population. Using a citizen-science survey, we investigate the relationship

69 between colony success and the landscape as a whole, accounting for all major land cover types

70 and also for the potential influence of hive management variables that vary between beekeepers.

71 Then, we specifically evaluate the putative favorability of urban land use using a subset of sites

72 dominated by urban development and/or cropland.

\section{Materials and Methods}

Survey Design. In 2012 and 2013, we used a survey-based, citizen-science approach to measure the productivity of honey bee colonies in the state of Ohio, USA. All participants were beekeepers whose hives were registered with the Ohio Department of Agriculture and who volunteered to participate in our study. Volunteers were enlisted through a combination of email communications, public speaking engagements, and cooperation with local beekeeping organizations; our study was publicized as widely as possible, and we did not attempt to target any particular demographic. Our survey was conducted with written exemption from IRB review by the Ohio State University Office of Responsible Research Practices (Protocol \# 2012E0136 and 2013E0012). In order to standardize the initial strength of the colonies in our study (hereafter "study colonies") and minimize the influence of parasites and pathogens, we restricted our study to colonies that had been started from artificial swarms, known as "package bees", in the spring of each study year. Honey bee packages are created by combining a standard quantity of worker bees (usually $1.36 \mathrm{~kg}$ ) with a newly mated queen. The initial strength of colonies started from 
88 package bees is, therefore, less variable than that of over-wintered colonies. Moreover, because

89 they are sold without comb or brood, they tend to have reduced parasite and pathogen loads.

90 Data for each study colony were gathered using a two-part survey consisting of spring and

91 fall components (hereafter "spring survey" and "fall survey"). The spring survey was made

92 available beginning in early March, and participants were instructed to complete the survey

93 immediately after installing their honey bee packages. In the spring survey, we gathered the

94 geographic location of each study colony and the years of experience of each participating

95 beekeeper (see S1 for full spring survey questionnaire). The fall survey was made available in

96 mid-September and completed by mid-October. To complete the fall survey, each participant

97 performed a frame-by-frame hive inspection and reported the number of frames in the study hive

98 belonging to the following categories: (1) more than half honey/nectar, (2) more than half pollen,

99 (3) more than half brood, (4) more than half empty wax comb, (5) more than half bare foundation

100 (no wax comb). Participants also reported the quantity of sugar syrup that had been given to their

101 hives as supplemental feeding, a common beekeeping practice that could affect colony success.

102 See S2 for full fall survey questionnaire.

103 Survey Processing. Each beekeeper was instructed to submit data for only one study hive

104 at one apiary site, and each beekeeper was included in only one of the two years of our study. The

105 data quality of all surveys was carefully vetted prior to analysis, and surveys missing critical data

106 or having irreconcilable inconsistencies were discarded. Fall surveys reporting hives that had died

107 since spring installation were also discarded. The final numbers of surveys included in analyses

108 for 2012 and 2013 were 32 and 18, respectively; these were selected from a pre-processing total

109 of 55 surveys in 2012 and 33 in 2013. The minimum distance between study hives, combing both

110 years, was $2.65 \mathrm{~km}$. 
112 accumulation, net wax production, adult population, and brood population. For consistency, all

113 metrics were recorded in units of standard deep frames.

114 Net food accumulation:

$$
\text { Food }=H+H_{\text {harv }}-H_{\text {add }}+P
$$

116 where $H=$ honey/nectar frames in hive at time of inspection, $H_{\text {harv }}=$ honey frames

117 harvested prior to inspection, $H_{a d d}=$ honey frames added to the hive prior to inspection

118 (beekeepers sometimes transfer honey frames between hives to increase food stores of weak

119 colonies), and $P=$ frames of pollen in hive at time of inspection. This variable will hereafter be

120 abbreviated Food.

121 Net wax production:

$$
\text { Wax }=H+H_{\text {harv }}+P+B+B_{r m}+D-H_{a d d}-B_{a d d}-D_{a d d}
$$
where $B=$ brood frames in hive at time of inspection, $B_{r m}=$ brood frames removed prior

124 to inspection (brood frames may be transferred between colonies to modulate population size), $D$

$125=$ drawn but mostly empty frames in hive at time of inspection, $B_{\text {add }}=$ brood frames added to the

126 hive prior to inspection, and $D_{a d d}=$ drawn but mostly empty frames (frames with wax comb

127 constructed but no cell contents) added to hive prior to inspection. This variable will hereafter be 128 abbreviated Wax.

129 Adult population (hereafter, AdultPop) was measured as the number of frames "more than 130 half covered" with adult bees at time of inspection. Brood population (hereafter, BroodPop) was

131 simply the number of "mostly brood" frames reported by the inspecting beekeeper.

132 We also measured two hive management variables: years of beekeeping experience of the 133 participating beekeeper (experience) and quantity of sugar syrup fed to the study hive since its 134 installation (syrup). 
135 Landscape Analysis. Geographic coordinates for each study hive were determined and

136 mapped using QGIS v. 2.1 (QGIS Development Team, 2014). To encompass a range of spatial

137 scales at which landscape effects on colony success might be seen, we defined the landscape of

138 each hive using six nested buffers having radii of $0.5,1,2,3,4$, and $5 \mathrm{~km}$, respectively. Land

139 cover data for the State of Ohio were obtained from the 2006 dataset provided by the National

140 Land Cover Database (NLCD 2006) (Fry et al., 2011). The NLCD 2006 land cover layer for Ohio

141 is comprised primarily of seven land cover classes: cultivated crops, pasture/hay, deciduous

142 forest, and four levels of urban development (open space, low intensity, medium intensity, high

143 intensity). Minor classes, present only at very low abundance, include evergreen forest, mixed

144 forest, woody wetland, herbaceous wetland, grassland/herbaceous, shrub/scrub, barren land, and

145 open water. To simplify our analysis of landscape composition, we condensed the non-crop land

146 cover classes (ignoring barren land and open water) into three aggregate classes: Forest

147 (deciduous + evergreen + mixed + woody wetland + shrub/scrub), Grassland (pasture/hay +

148 grassland/herbaceous + herbaceous wetland), and Urban (open space + low intensity + medium

149 intensity + high intensity). The landscape composition of each study site, measured in terms of

150 the total land cover of Crop (cultivated crop) and each aggregate class, was determined at each

151 spatial scale using LECOS (Jung, 2013), a QGIS plugin for calculating patch-based landscape

152 metrics. As a measure of overall landscape heterogeneity, we also calculated Simpson’s Diversity

153 Index $(D)$ based on the original, non-aggregated land cover classes.

154 Data Analysis. We first reduced the dimensionality of our landscape data using principal

155 components analysis (PCA) based on the covariance between the variables Crop, Forest,

156 Grassland, and Urban. This step was repeated for each spatial scale. For all scales, the first two

157 principal components ( $P C 1$ and $P C 2$ ) explained $>96 \%$ of total variance. 

also for the management variables experience and syrup, we conducted model selection using

160 Akaike's Information Criterion corrected for small sample size ( $\left.\mathrm{AIC}_{\mathrm{c}}\right)($ Burnham \& Anderson, 161 2002). Each success metric--Food, Wax, AdultPop, and BroodPop--was modeled separately.

162 Fourteen candidate linear models were constructed for each success metric at each spatial scale;

163 these included all combinations of the landscape variables $(P C 1, P C 2, D)$ and the coupled

164 management variables experience and syrup, a year-only model, and an intercept-only model. For

165 each success metric, we present the candidate model having the lowest AICc score at each scale

166 along with any competing models having an $\mathrm{AIC}_{\mathrm{c}}$ difference of $<2$ (Table 1) (Burnham \&

167 Anderson, 2002). We then selected a single best model for each success metric by choosing the

168 model with the lowest $\mathrm{AIC}_{\mathrm{c}}$ score across all spatial scales.

169 To evaluate the prediction that urban land cover favors honey bee success relative to

170 agricultural land cover, we first extracted the subset of our sites $(n=30$ to 33 , varying with

171 spatial scale) for which Urban + Crop was greater than 50\% of total landcover, a threshold

172 chosen a priori to identify sites that were strongly characterized by urban and/or agricultural land

173 use. Then, we then set up separate linear regression models for Food and Wax with Urban as the

174 explanatory variable. Only Food and Wax were analyzed because the results of the PCA

175 described above indicated that only these two success metrics should be expected to respond to

176 landscape variables. We did not use experience and syrup as covariates because previous analysis

177 showed they were not predictive of Food or Wax. Regression analysis was repeated for each

178 spatial scale.

179 All analysis was performed in R statistical software (R Core Team, 2014). AIC $\mathrm{C}_{\mathrm{c}}$ model

180 selection used the package AICcmodavg (Mazerolle, 2014). Model assumptions were verified

181 by visual assessment using the plot ( $1 \mathrm{~m}$ ) function in R. 


\section{Results}

Landscape analysis. The landscapes surrounding the colonies in our survey represented a

184 broad range of landscape composition in terms of the major land cover classes Crop, Forest,

185 Grassland, and Urban (Fig. 1). Principal components analysis of these four variables yielded

186 two readily interpretable axes that explained greater than $96 \%$ of total variance (Fig. 2). $P C 1$ was

187 essentially an urban-rural axis, with sites dominated by Urban scoring low and sites dominated

188 by combinations of Crop, Forest, and/or Grassland scoring high. PC 2 partitioned non-urban

189 landscapes into those characterized by Crop and those characterized by Forest and, to a lesser

190 extent, Grassland.

Modeling colony success metrics by landscape principal components. Food and Wax

192 were best modeled with $P C 2$ as the only explanatory variable. Almost all competing models

$193\left(\triangle \mathrm{AIC}_{\mathrm{c}}<2\right)$ included $P C 2$ alongside other explanatory variables, further supporting the

194 conclusion that $P C 2$ was the single most important predictor (Table 1). For Food, the optimal

195 spatial scale was a $1 \mathrm{~km}$ radius, while Wax was best predicted at a $2 \mathrm{~km}$ radius. In both cases, the

196 relationship was negative and the linear regression models were statistically significant (Food: F

$197=4.796, \mathrm{df}=48, p=0.033 ; \operatorname{Wax}: F=6.184, \mathrm{df}=48, p=0.016)$ (Fig. 3). AdultPop was best

198 modeled with the coupled management variables experience and syrup as the only explanatory

199 variables. The relationship was positive and the linear regression model was significant $(F=$

$2006.128, \mathrm{df}=47, p=0.004)$, with significant contributions from both experience $(t=2.98, \mathrm{df}=47$,

$201 p=0.005)$ and $\operatorname{syrup}(t=2.474, \mathrm{df}=47, p=0.017)$ (Fig. 4). BroodPop was best predicted by the

202 intercept-only model, indicating that none of our measured explanatory variables were good

203 predictors of this success metric.

204 Modeling colony success metrics by urban landcover. We found a significant $(p<0.05)$

205 negative relationship between Food and Urban (Fig. 5) at all spatial scales except for the two 
206

207

208

209

210

211

212

213

214

215

216

217

218

219

220

221

222

223

224

225

226

227

228

extremes of $0.5 \mathrm{~km}$ and $5 \mathrm{~km}$.; the relationship was strongest at the $2 \mathrm{~km}$ scale $(F=6.041, \mathrm{df}=$ $29, p=0.02)$. Wax was not significantly related to the Urban $(p>0.05)$.

Discussion

The negative responses of Food and Wax to PC 2 indicate that food accumulation and wax production increase with surrounding cropland and decrease with forest/grassland. This finding seems to contradict the conventional wisdom that agricultural land conversion threatens honey bee nutrition through the depauperation of floral resources relative to semi-natural environments (De La Rúa et al., 2009), but is consistent with studies that have found honey bees to be notably resilient to natural habitat loss compared to other bee taxa (Ricketts et al., 2008;

Winfree et al., 2009). The productivity of honey bees does not depend so much on the presence of undisturbed natural floral communities as it does on the availability of rich resources that can be exploited efficiently by cooperative foraging (Visscher \& Seeley, 1982), and agricultural environments can offer honey bees surprisingly rich floral resources in the form of "weeds" (Odoux et al., 2012; Requier et al., 2014). In Ohio, the largest honey yield is believed to come from non-native clovers (Trifolium spp. L.) (Pellett, 1920; Bailey, 1955; Goltz, 1975); these plants grow abundantly along roadsides, in field margins, and in grassy yards, but they are scarce in habitats shaded by forest canopy or dominated by the dense herbaceous vegetation of unmowed grassland. In addition to the clovers, Erickson (Erickson, 1984) observed that, under some conditions, honey bees will forage very productively on soybean (Glycine max (L.) Merr.), and corn/soybean rotations comprise the vast majority of Ohio cropland. Dandelion (Taraxacum officinale F. H. Wigg.), one of the most important spring flora for honey bees in the Midwest (Jaycox, 1976) during the period of peak wax production, is distributed in much the same pattern as the clovers, thus favoring wax production in cropland over seminatural forest and grassland. 
230 forest/grassland is strikingly consistent with an anecdotal description of regional honey

231 production in Ohio published nearly forty years ago (Goltz, 1975). In Goltz' account, the areas of

232 "primary" and "secondary" importance for honey production are in the heavily cultivated glacial

233 plains that comprise most of the state, while the forest-dominated Appalachian Plateaus in the

234 southeast are described as only "marginally" productive.

235 The positive response of AdultPop to the management variables experience and syrup is

236 difficult to interpret. In early spring, when new colonies are very small and limited in their

237 foraging ability, it is standard practice to supplement colony nutrition with sugar syrup. All

238 workers produced during the period of spring build-up, though, died long before colonies were

239 inspected in the fall, so any positive effect of the springtime management on adult population at

240 time of inspection would have to be mediated by factors that allow colonies to increase

241 reproduction later in the year. An alternative interpretation is plausible if we allow that significant

242 feeding may have occurred later in the year. While supplemental feeding is normally concentrated

243 in early spring, some Ohio beekeepers also feed their colonies in mid-late summer, a period of

244 perceived dearth in natural forage. Feeding during the summer dearth period might trigger a

245 population increase that would persist until fall inspection. Our survey did not distinguish

246 between feeding at different times during the season. The effect of beekeeper experience on adult

247 population is difficult to parse, as all aspects of hive management would be expected to improve

248 on average with increasing experience. Somewhat ironically, a positive relationship between

249 colony success and beekeeper experience might be explained by the tendency of more

250 experienced beekeepers to perform less colony management; the enthusiasm of new beekeepers

251 can lead to unnecessary interventions that do more to disturb natural colony function than to

252 ameliorate ills (James Tew, pers. comm., 2014). 
254 the fall survey, the bees had likely already begun to reduce brood rearing in preparation for winter

255 (Graham, 1992). This would explain the failure of both landscape and management variables in

256 predicting BroodPop.

257

258

259

260

261

262

263

264

265

266

267

268

269

270

271

272

273

274

275

276

277

The negative relationship observed between Food and the ratio of Urban in the subset of our sites strongly characterized by urban and/or agricultural land use does not support the popular opinion that urban landscapes favor honey bee success relative to agricultural landscapes. At least in Ohio, the relationship appears to be the opposite, and the fact that Food was the only success metric to respond to Urban ratio suggests a likely mechanism. The last major nectar and pollen flow in Ohio is usually from goldenrod (Solidago spp. L.) (Morse, 1972; D. B. Sponsler, unpublished data), which blooms prolifically from late summer into fall, roughly the same period during which beekeepers in our study were conducting fall hive inspections and filling out the fall survey. At this time of year, honey bees rarely produce additional wax (Lee \& Winston, 1985), and brood rearing has begun to slow down in preparation for winter (Graham, 1992), so incoming food is stored rather than being invested in brood or wax production. Goldenrod occurs abundantly in uncultivated fields and conservation strips throughout agricultural landscapes, but it is relatively scarce in developed areas where vegetation is more often subject to mowing and weed control. This is consistent with the anecdotal observation of Burgett et al. (1978) that urban hives tend to have poor late-season honey production, which the authors attribute to scarcity of late-blooming "weeds", including goldenrod.

We conclude that both landscape composition and colony management contribute to the success of nascent honey bee colonies in our study region. Due to complexities not explored in this study, the prediction of colony success was partitioned such that landscape predicted food accumulation and wax production, while colony management predicted only adult worker population. We find no support for the opinion that honey bees in urban landscapes are more 
278

279

280

281

282

283

284

285

286

287

288

289

290

291

292

293

294

295

296

297

298

299 successful than those in cropland. To the contrary, we find that colony food accumulation

responds negatively to to to urban land cover in landscapes dominated by urban or agricultural land use, a pattern that we attribute to the influence of late-season floral availability, particularly goldenrod.

It is important to note that the while model selection identified landscape composition as the best predictor of colony food and wax accumulation, the amount of unexplained variation in our models was high, indicating that factors other than the ones we measured are also at play in the determination of colony success. Such factors may include (1) fine-scale landscape variables that were not measurable using the NLCD dataset, (2) hive management variables not accounted for in our beekeeper survey, and (3) "in-hive" determinants of colony success like queen fertility, disease prevalence, and parasite load. We also suggest caution in generalizing our results beyond our study region. While the landscape of Ohio is broadly similar to much of the American Midwest, it would be premature to extend our findings to other ecoregions that may differ strongly both in natural flora and in agricultural practices.

\section{Acknowledgments}

We sincerely thank the many Ohio beekeepers whose participation made this project possible. C. Hoy and M. Gardiner provided helpful statistical consultation, and J. O. QuijiaPillajo assisted in GIS analysis.

\section{References}

Bailey SE, 1955. Beekeeping in Ohio. Gleanings in Bee Culture, 83:723-725.

Beekman M, Ratnieks F. 2001. Long-range foraging by the honey-bee, Apis mellifera L. Functional Ecology, 14:490-496. 
300 Burgett M, Caron DM, Ambrose JT. 1978. Urban apiculture. Perspectives in Urban Entomology.

301 Ed. GW Frankie and CS Kohler. Academic Press, New York. 187-219.

302 Burnham KP, Anderson DR. 2002. Model selection and multimodel inference. Springer, New

$303 \quad$ York.

304 Couvillon MJ, Schürch R, Ratnieks FLW. 2014. Dancing bees communicate a foraging

305 preference for rural lands in high-level agri-environment schemes. Current Biology, 24:1-

3064 .

307 De La Rúa P, Jaffé R, Dall’Olio R, Muñoz I, Serrano J. 2009. Biodiversity, conservation and

308 current threats to European honeybees. Apidologie, 40:263-284.

309 Donkersley P, Rhodes G, Pickup RW, Jones KC, Wilson K. 2014. Honeybee nutrition is linked to landscape composition. Ecology and Evolution 4:4195-4206.

311 Eckert JE. 1931. The flight range of the honeybee. Journal of Agricultural Research, 47:257$312 \quad 285$.

313 Erickson EH. 1984. Soybean pollination and honey production--a research progress report. American Bee Journal, 124:775-779.

315 Frisch von K. 1967. The dance language and orientation of bees. The Belknap Press of Harvard $316 \quad$ University, Cambridge, Massachusetts.

317 Fry JA, Xian G, Jin S, Dewitz JA, Homer CG, Limin Y, Barnes CA, Herold ND, Wickham JD.

318 2011. Completion of the 2006 national land cover database for the conterminous United $319 \quad$ States. Photogrammetric Engineering and Remote Sensing, 77:858-864.

320 Garbuzov M, Schürch R, and Ratnieks FLW. 2014. Eating locally: dance decoding demonstrates

321 that urban honey bees in Brighton, UK, forage mainly in the surrounding urban area.

$322 \quad$ Urban Ecosystems 1-8. 
323 Goulson D, Hughes W, Derwent L, Stout J. 2002. Colony growth of the bumblebee, Bombus

324 terrestris, in improved and conventional agricultural and suburban habitats. Oecologia,

$325 \quad 130: 267-273$.

326 Goulson D, Lepais O, O’Connor S, Osborne JL, Sanderson RA, Cussans J, Goffe L, Darvill B.

327 2010. Effects of land use at a landscape scale on bumblebee nest density and survival.

$328 \quad$ Journal of Applied Ecology, 47:1207-1215.

329 Goltz L. 1975. Beekeeping in Ohio. Gleanings in Bee Culture, 103:22,25.

330 Graham JM. 1992. The hive and the honey bee. Dadant \& Sons, Hamilton, Illionois.

331 Härtel S, Steffan-Dewenter I. 2014. Ecology: Honey Bee Foraging in Human-Modified

332 Landscapes. Current Biology, 24:R524-R526.

333 Jaycox ER. 1976. Beekeeping in the Midwest [USA]. Circular - Illinois University.

334 Lee PC, Winston ML. 1985. The effect of swarm size and date of issue on comb construction in

335 newly founded colonies of honeybees (Apis mellifera L.). Canadian Journal of Zoology,

$336 \quad 63: 524-527$.

337 Morse RA. 1972. The complete guide to beekeeping. E. P. Dutton \& CO., Inc, New York.

338 Naug D. 2009. Nutritional stress due to habitat loss may explain recent honeybee colony

$339 \quad$ collapses. Biological Conservation, 142:2369-2372.

340 New York Times (anonymous). 2008. French bees find a haven in Paris. Retrieved from:

341 http://www.nytimes.com/2008/10/01/health/01iht-parisbees.16613547.html?

$342 \stackrel{\mathrm{r}=1 \& \text { pagewanted }=\text { print }}{\underline{2}}$

343 Odoux J-F, Feuillet D, Aupinel P, Loublier Y, Tasei J-N, Mateescu C. 2012. Territorial

$344 \quad$ biodiversity and consequences on physico-chemical characteristics of pollen collected by

$345 \quad$ honey bee colonies. Apidologie 43:561-575 
Odoux J-F, Aupinel P, Gateff S, Requier F, Henry M, Bretagnolle V. 2014. ECOBEE: a tool for long-term honey bee colony monitoring at the landscape scale in West European intensive agroecosystems. Journal of Apicultural Research 53:57-66.

Pellett FC. 1920. American honey plants: together with those which are of special value to the beekeeper as sources of pollen. American Bee Journal, Hamilton, Illinois.

R Core Team (2013). R: A language and environment for statistical computing. R Foundation for Statistical Computing, Vienna, Austria. URL http://www.R-project.org/

Requier F, Odoux, J-F, Tamic T, Moreau N, Henry M, Decourtye A, Bretagnolle V. (accepted). Honey bee diet in intensive farmland habitats reveals an unexpectedly high flower richness and a major role of weeds. Ecological Applications Preprint.

Ricketts TH, Regetz J, Steffan-Dewenter I, Cunningham SA, Kremen C, Bogdanski A, Gemmill2008. Landscape effects on crop pollination services: are there general patterns? Ecology higher honey yield: Another reason to conserve. Biological Conservation 142:2703-2709.

Steffan-Dewenter I, Kuhn A. 2003. Honeybee foraging in differentially structured landscapes. Proceedings of the Royal Society B: Biological Sciences, 270:569-575. Invertebrate Pathology, 103:S80-S95. 
370 Waddington KD, Herbert TJ, Visscher PK, Richter MR. 1994. Comparisons of forager

371 distributions from matched honey bee colonies in suburban environments. Behavioral

372 Ecology and Sociobiology, 35:423-429.

373 Wilson-Rich N. 2012. Every city needs healthy honey bees. Recorded presentation. Retrieved

374 from:http://www.ted.com/talks/noah_wilson_rich_every_city_needs_healthy_honey_bees

$375 \quad$ ?language $=$ en

376 Winfree R, Aguilar R, Vázquez DP, LeBuhn G, Aizen MA. 2009. A meta-analysis of bees' responses to anthropogenic disturbance. Ecology, 90:2068-2076. 
Table $\mathbf{1}$ (on next page)

Summary of model selection statistics for each colony success metric.

Table 1: Summary of model selection statistics for each colony success metric. Only models with $\triangle \mathrm{AIC}_{\mathrm{c}}<2$ are presented a competing models. Models within each spatial scale are listed in order of increasing $\mathrm{AlC}_{\mathrm{c}}$ value. The best model for each success metric is depicted in bold. 


\begin{tabular}{|c|c|c|c|c|c|c|c|c|c|}
\hline Metric & Radius (km) & Model & Log-likelihood & $K_{i}$ & $A / C_{c}$ & $\triangle A / C_{c}$ & $W_{i}$ & Adjusted $\mathrm{r}^{2}$ & Coefficients \\
\hline Food & 0.5 & PC2 & -165.808 & 3 & 338.138 & 0.00 & 0.233 & 0.047 & -5.9142 \\
\hline$"$ & 0.5 & $P C 1+P C 2$ & -165.060 & 4 & 339.008 & 0.87 & 0.151 & 0.055 & $P C 2=-5.9142, P C 1=2.5032$ \\
\hline$"$ & 0.5 & intercept & -167.515 & 2 & 339.286 & 1.15 & 0.563 & 0.131 & \\
\hline " & 1 & PC2 & -165.134 & 3 & 336.791 & 0.00 & 0.260 & 0.072 & -7.3139 \\
\hline$"$ & 1 & $P C 1+P C 2$ & -164.175 & 4 & 337.240 & 0.45 & 0.208 & 0.088 & $P C 2=-7.3139, P C 1=2.9608$ \\
\hline " & 2 & PC2 & -165.686 & 3 & 337.894 & 0.00 & 0.197 & 0.051 & -6.541 \\
\hline " & 2 & $P C 1+P C 2$ & -164.553 & 4 & 337.995 & 0.10 & 0.187 & 0.074 & $P C 2=-6.5409, P C 1=3.5536$ \\
\hline " & 2 & intercept & -167.515 & 2 & 339.286 & 1.39 & 0.499 & 0.098 & \\
\hline " & 2 & $P C 1+P C 2+D$ & -163.990 & 5 & 339.343 & 1.45 & 0.095 & 0.075 & $P C 2=-7.529, P C 1=5.195, D=7.674$ \\
\hline " & 2 & PC1 & -166.464 & 3 & 339.450 & 1.56 & 0.090 & 0.021 & 3.5536 \\
\hline " & 3 & $\mathrm{PC} 2$ & -165.871 & 3 & 338.265 & 0.00 & 0.183 & 0.044 & -6.0981 \\
\hline$"$ & 3 & $P C 1+P C 2$ & -164.733 & 4 & 338.355 & 0.09 & 0.175 & 0.067 & $P C 2=-6.0981, P C 1=3.7970$ \\
\hline$"$ & 3 & intercept & -167.515 & 2 & 339.286 & 1.02 & 0.600 & 0.110 & \\
\hline " & 3 & PC1 & -166.451 & 3 & 339.424 & 1.16 & 0.103 & 0.022 & 3.7970 \\
\hline$"$ & 3 & $P C 1+P C 2+D$ & -164.247 & 5 & 339.858 & 1.59 & 0.083 & 0.065 & $P C 2=-6.554, P C 1=5.729, D=7.200$ \\
\hline " & 4 & $\mathrm{PC} 2$ & -166.135 & 3 & 338.791 & 0.00 & 0.179 & 0.034 & -5.5831 \\
\hline " & 4 & intercept & -167.515 & 2 & 339.286 & 0.49 & 0.781 & 0.140 & \\
\hline " & 4 & $P C 1+P C 2$ & -165.202 & 4 & 339.293 & 0.50 & 0.139 & 0.050 & $P C 2=-5.5831, P C 1=3.5906$ \\
\hline " & 4 & PC1 & -166.634 & 3 & 339.789 & 1.00 & 0.109 & 0.015 & 3.5906 \\
\hline " & 5 & PC2 & -166.203 & 3 & 338.928 & 0.00 & 0.174 & 0.031 & -5.378 \\
\hline
\end{tabular}




\begin{tabular}{|c|c|c|c|c|c|c|c|c|c|}
\hline$"$ & 5 & intercept & -167.515 & 2 & 339.286 & 0.36 & 0.836 & 0.145 & \\
\hline$"$ & 5 & $\mathrm{PC} 1+\mathrm{PC} 2$ & -165.269 & 4 & 339.428 & 0.50 & 0.135 & 0.047 & $P C 2=-5.3783, P C 1=3.6745$ \\
\hline$"$ & 5 & PC1 & -166.630 & 3 & 339.782 & 0.85 & 0.113 & 0.015 & 3.6745 \\
\hline Wax & 0.5 & PC2 & -180.163 & 3 & 366.848 & 0.00 & 0.242 & 0.041 & -7.525 \\
\hline$"$ & 0.5 & Year & -180.538 & 3 & 367.598 & 0.75 & 0.687 & 0.167 & 0.02648 \\
\hline$"$ & 0.5 & intercept & -181.724 & 2 & 367.704 & 0.86 & 0.652 & 0.158 & \\
\hline$"$ & 1 & PC2 & -179.240 & 3 & 365.001 & 0.00 & 0.299 & 0.076 & -9.917 \\
\hline$"$ & 1 & $P C 2+D$ & -178.958 & 4 & 366.804 & 1.80 & 0.122 & 0.067 & $P C 2=-8.892, D=-6.540$ \\
\hline$"$ & 2 & PC2 & -178.695 & 3 & 363.911 & 0.00 & 0.341 & 0.096 & -11.053 \\
\hline$"$ & 2 & $P C 2+D$ & -178.388 & 4 & 365.665 & 1.75 & 0.142 & 0.088 & $P C 2=-10.247, D=-6.265$ \\
\hline " & 2 & $\begin{array}{l}\mathrm{PC} 2+\text { years }+ \\
\text { syrup }\end{array}$ & -177.249 & 5 & 365.862 & 1.95 & 0.129 & 0.109 & $\begin{array}{l}\text { PC2 }=-11.8583, \text { years }=0.1252, \text { syrup }= \\
0.2578\end{array}$ \\
\hline$"$ & 3 & PC2 & -179.076 & 3 & 364.673 & 0.00 & 0.278 & 0.082 & -10.183 \\
\hline$"$ & 3 & $P C 2+D$ & -178.374 & 4 & 365.636 & 0.96 & 0.172 & 0.088 & $P C 2=-9.611, D=-9.020$ \\
\hline " & 3 & $\begin{array}{l}\mathrm{PC} 2+\text { years }+ \\
\text { syrup }\end{array}$ & -177.453 & 5 & 366.270 & 1.60 & 0.125 & 0.102 & $\begin{array}{l}\text { PC2 }=-11.4033, \text { years }=0.1346, \text { syrup }= \\
0.2765\end{array}$ \\
\hline$"$ & 4 & $\mathrm{PC} 2^{*}$ & -179.411 & 3 & 365.344 & 0.00 & 0.260 & 0.069 & -9.514 \\
\hline$"$ & 4 & $P C 2+D$ & -178.721 & 4 & 366.331 & 0.99 & 0.159 & 0.075 & $P C 2=-9.281, D=-8.998$ \\
\hline " & 4 & $\begin{array}{l}\mathrm{PC} 2+\text { years }+ \\
\text { syrup }\end{array}$ & -177.827 & 5 & 367.017 & 1.67 & 0.113 & 0.089 & $\begin{array}{l}\text { PC2 }=-10.7781, \text { years }=0.1244, \text { syrup }= \\
0.2762\end{array}$ \\
\hline$"$ & 5 & $\mathrm{PC} 2^{*}$ & -179.465 & 3 & 365.451 & 0.00 & 0.255 & 0.067 & -9.290 \\
\hline$"$ & 5 & $P C 2+D$ & -178.750 & 4 & 366.389 & 0.94 & 0.159 & 0.074 & $P C 2=-9.253, D=-9.112$ \\
\hline " & 5 & $\begin{array}{l}\text { PC2 + years + } \\
\text { syrup }\end{array}$ & -177.865 & 5 & 367.095 & 1.64 & 0.112 & 0.087 & $\begin{array}{l}\text { PC2 }=-10.5842, \text { years }=0.1317, \text { syrup }= \\
0.2776\end{array}$ \\
\hline
\end{tabular}




\begin{tabular}{|c|c|c|c|c|c|c|c|c|c|}
\hline AdultPop & 2 & $\begin{array}{l}\mathrm{PC} 2+\text { years }+ \\
\text { syrup }\end{array}$ & -160.864 & 5 & 333.092 & 1.47 & 0.205 & 0.172 & $\begin{array}{l}\mathrm{PC} 2=-3.0878, \text { years }=0.4904, \text { syrup }= \\
0.2896\end{array}$ \\
\hline " & 3 & $\begin{array}{l}\mathrm{PC} 2+\text { years + } \\
\text { syrup }\end{array}$ & -160.590 & 5 & 332.544 & 0.92 & 0.247 & 0.181 & PC2: -3.7837 , years: 0.4939 , syrup: 0.2991 \\
\hline$"$ & 4 & $\begin{array}{l}\text { PC2 + years + } \\
\text { syrup }\end{array}$ & -160.652 & 5 & 332.668 & 1.05 & 0.235 & 0.179 & $\begin{array}{l}P C 2=-3.6243, \text { years }=0.4906, \text { syrup }= \\
0.2993\end{array}$ \\
\hline$"$ & 4 & $D+$ years + syrup & -161.090 & 5 & 333.544 & 1.92 & 0.151 & 0.164 & D: 4.2943 , years: 0.5219 , syrup: 0.3059 \\
\hline " & 5 & $\begin{array}{l}\mathrm{PC} 2+\text { years }+ \\
\text { syrup }\end{array}$ & -160.634 & 5 & 332.631 & 1.01 & 0.234 & 0.180 & $\begin{array}{l}\mathrm{PC} 2=-3.6267, \text { years }=0.4931, \text { syrup }= \\
0.3002\end{array}$ \\
\hline$"$ & 5 & $D+$ years + syrup & -161.002 & 5 & 333.367 & 1.75 & 0.162 & 0.167 & $D=4.9270$, years $=0.5308$, syrup $=0.3094$ \\
\hline " & NA & years + syrup & -161.365 & 4 & 331.620 & 0.00 & 0.475 & 0.173 & years $=0.4887$, syrup $=0.2774$ \\
\hline
\end{tabular}


Figure $\mathbf{1}$ (on next page)

Landscape composition of study sites at $2 \mathrm{~km}$ radius

Figure 1: Landscape composition of study sites at $\mathbf{2} \mathbf{~ k m}$ radius. Sites are depicted in order of increasing urban (red) land cover. Other major land cover classes include crop (gold), forest (dark green), and grassland (light green). Remaining land cover (grey) consisted of barren land and open water. 


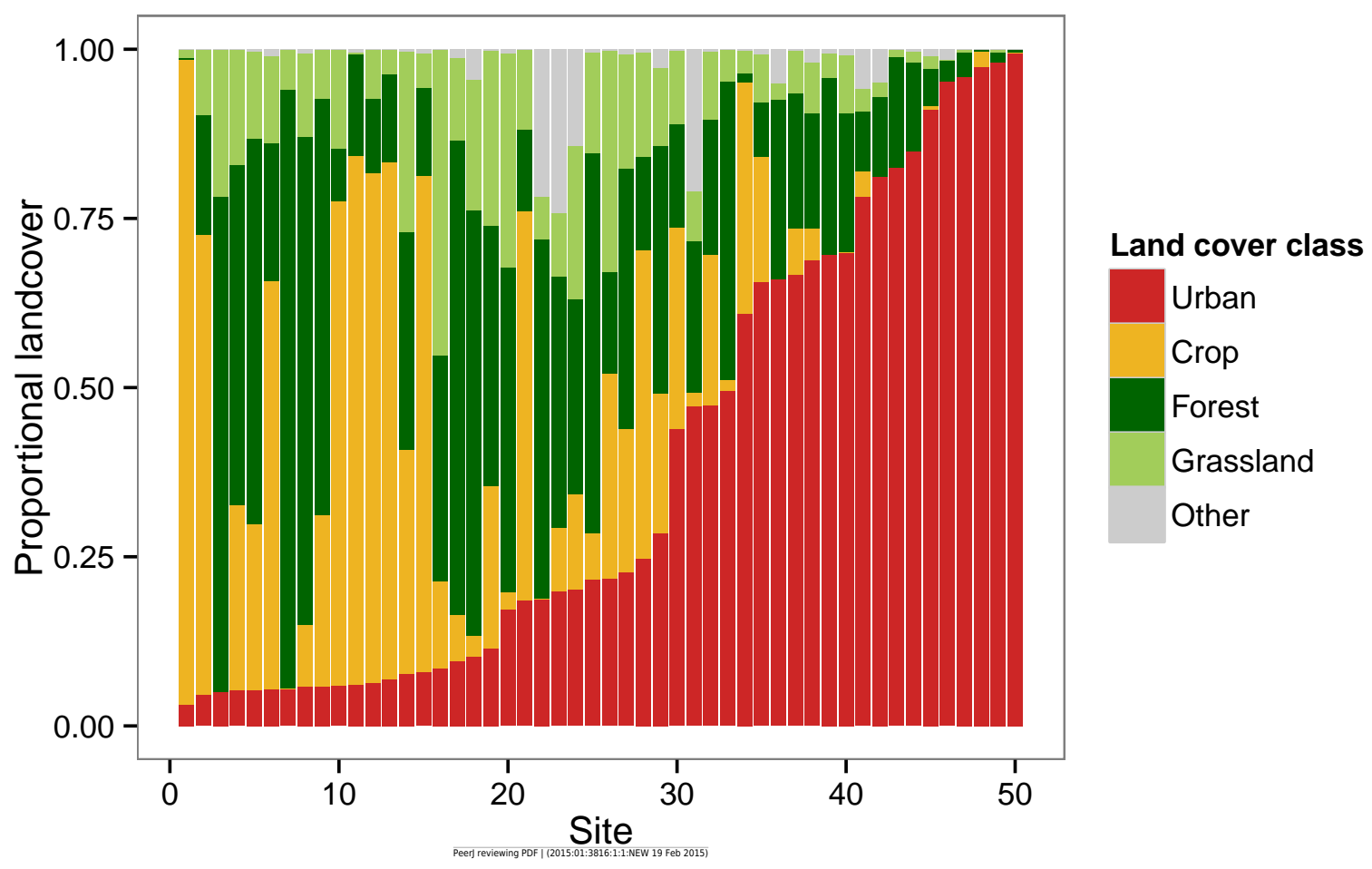


Figure 2 (on next page)

Principal components biplot of major land cover classes at a radius of $2 \mathrm{~km}$

Figure 2: Principal components biplot of major land cover classes at a radius of 2

km. Principal component 1 (PC 1) comprises an urban-rural axis, with lower scores corresponding to higher urbanness. Principal component 2 (PC 2) forms an axis that separates sites characterized by forest/grassland from those characterized by cropland. This pattern was consistent at all spatial scales with only minor variation. 
Figure 3 (on next page)

Food accumulation and wax production negatively correlated with PC 2

Figure 3: Food accumulation (A) and wax production (B) were negatively correlated with PC 2. This indicates that productivity in terms of food and wax increased in the direction of cropland and decreased in the direction of forest/grassland. A 95\% confidence band is shaded in gray. 

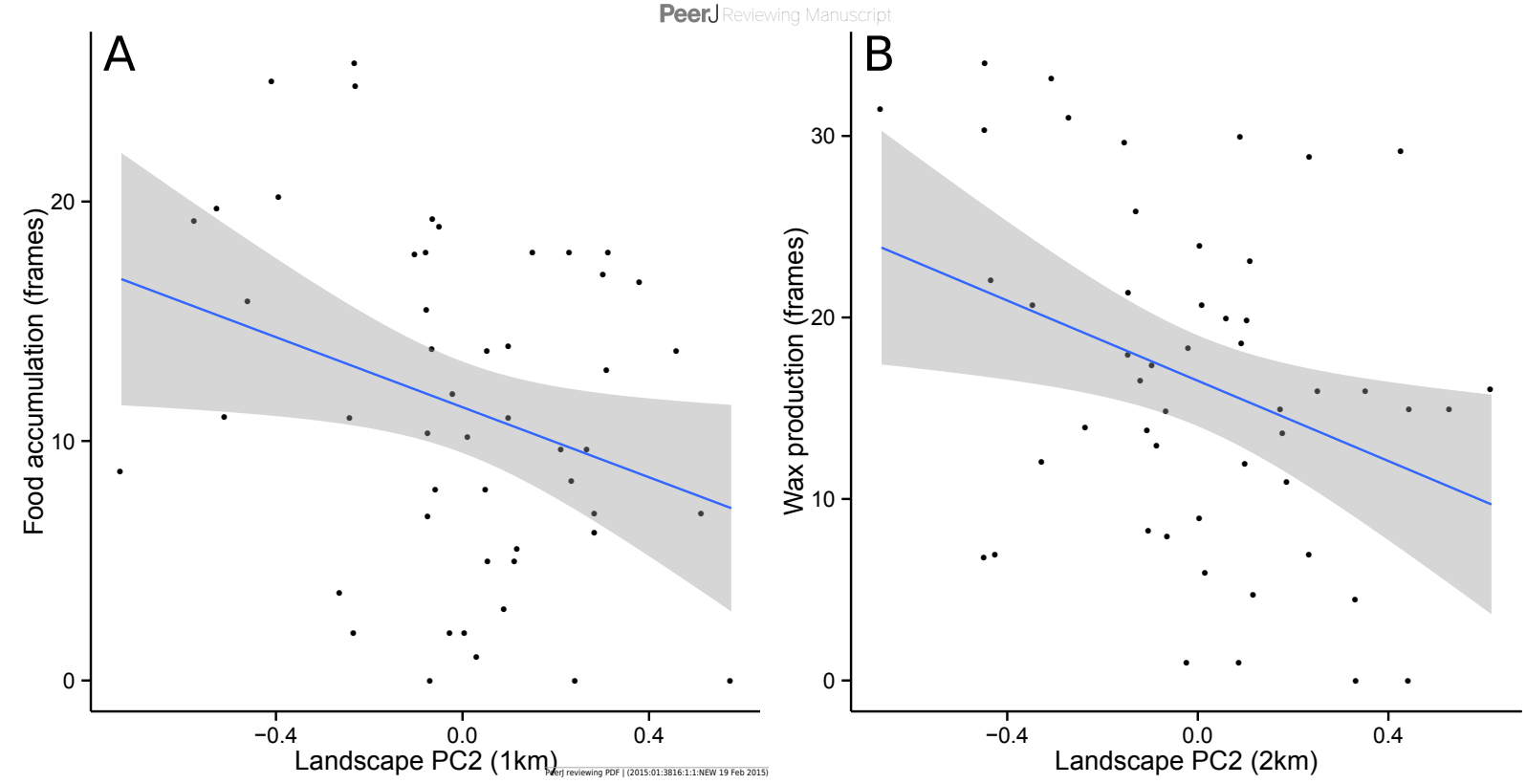
Figure 4 (on next page)

Adult population positively correlated with beekeeper years of experience and supplemental syrup feeding.

Figure 4: Adult population was positively correlated with beekeeper years of

experience (A) and supplemental syrup feeding (B). A 95\% confidence band is shaded in gray. 


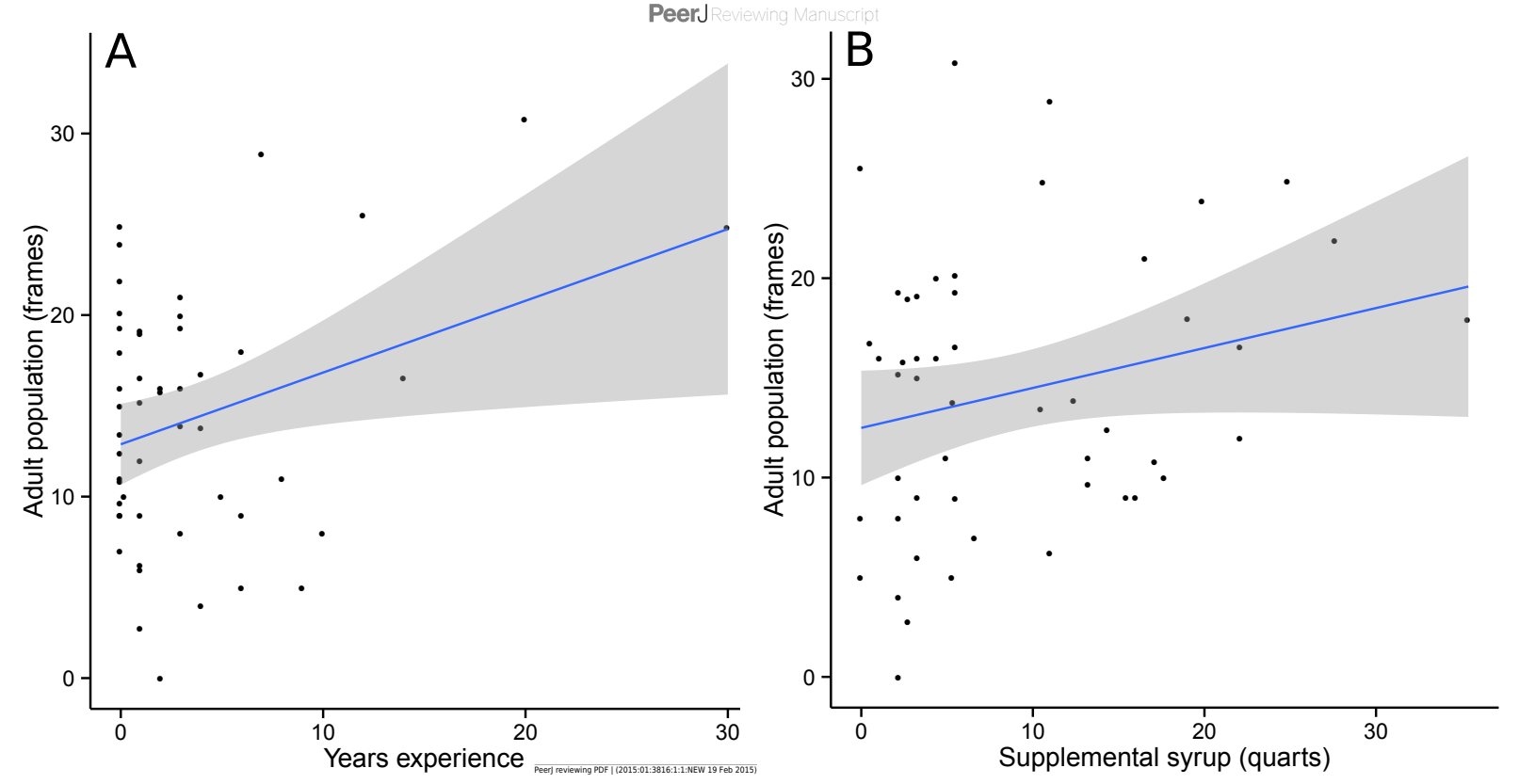


Figure 5 (on next page)

Colony food accumulation decreased significantly with increasing urban land cover in sites where Urban + Crop > 50\%

Figure 5: Colony food accumulation decreased significantly with increasing urban land cover in sites where Urban + Crop $>\mathbf{5 0 \%}$. This pattern was strongest at a $1 \mathrm{~km}$ radius (shown above). A $95 \%$ confidence band is shaded in gray. 
PeerJ Reviewing Manuscript

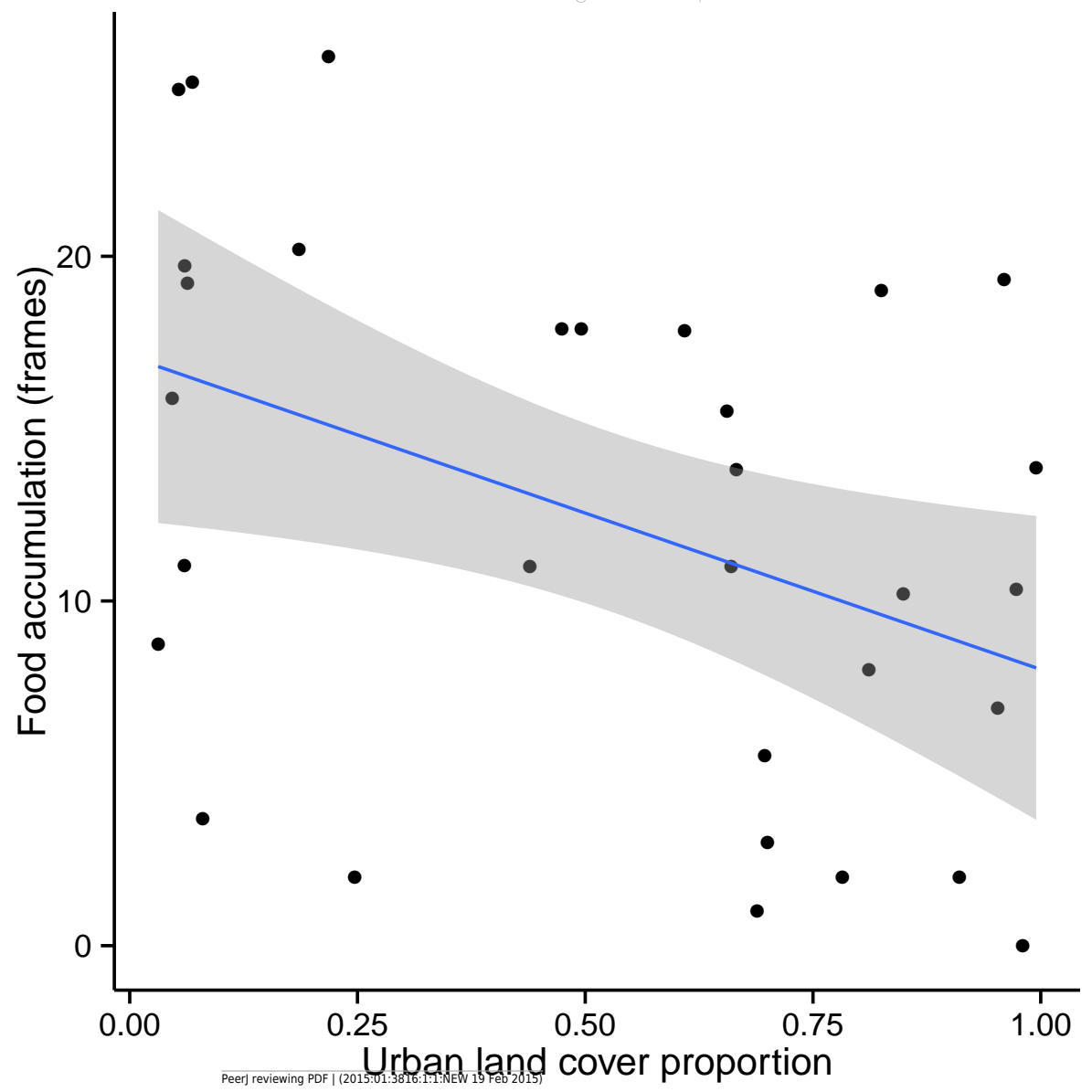

